\title{
Regulation of Episodic Growth Hormone Secretion by the Central Epinephrine System
}

\author{
STUDIES IN THE CHRONICALLY CANNULATED RAT
}

\author{
L. Cass Terry, W. R. Crowley, and M. D. Johnson, Departments of Neurology \\ and Pharmacology, Veterans Administration Medical Center Research \\ Service, University of Tennessee Center for Health Sciences, Memphis, \\ Tennessee 38104
}

A B S T R A C T Catecholamines are postulated to regulate growth hormone (GH) secretion by their influence on the release of two hypothalamic substances, somatostatin, which inhibits GH release, and GH-releasing factor, as yet unidentified. Extensive pharmacologic studies in man and animals indicate a stimulatory effect of central norepinephrine and dopamine on GH, but the function of epiphephrine (EPI) is uncertain. Furthermore, many of the agents used to study the role of catecholamines in $\mathrm{GH}$ regulation are not selective in that they affect adrenergic as well as noradrenergic and/or dopaminergic neurotransmission. In the present investigation, central nervous system (CNS) EPI biosynthesis was selectively interrupted with the specific norepinephrine $N$-methyltransferase inhibitors, SK \& F 64139 (Smith, Kline \& French Laboratories) and LY 78335, (Eli Lilly \& Co. Research Laboratories) and the effects of central EPI depletion on episodic GH secretion in the chronically cannulated rat model were determined. Inhibition of CNS EPI synthesis with SK\&F 64139 caused complete suppression of episodic $\mathrm{GH}$ secretion and concomitantly reduced the EPI level in the hypothalamus without affecting dopamine or norepinephrine. Administration of LY 78335 produced similar effects on pulsatile $\mathbf{~ G H}$. Morphine-induced, but not clonidine-induced, GH release also was blocked by SK\& F 64139. These results indicate that $(a)$ the central EPI system has a major stimulatory function in episodic $\mathrm{GH}$ release, $(b)$ morphine-induced $\mathrm{GH}$ release is mediated by the central EPI system, and (c) clonidine stimulates $\mathrm{GH}$ release by activation of postsynaptic $\alpha$-adrenergic receptors.

L. C. Terry is the recipient of a Clinical Investigator Award from the Veterans Administration.

Received for publication 27 March 1981 and in revised form 9 September 1981.
Drugs that affect CNS adrenergic systems have a potential role in the diagnosis and treatment of disorders of $\mathrm{GH}$ secretion.

\section{INTRODUCTION}

Growth hormone $(\mathrm{GH})^{1}$ secretion by the pituitary gland appears to be regulated by two hypothalamic hormones, one stimulatory (GH-releasing factor) and the other inhibitory (somatostatin). Although there is substantial physiological and biochemical evidence for the existence of GH-releasing factor, its structure has not been determined (1). Somatostatin has been characterized as a tetradecapeptide (2). Extensive studies in man and experimental animals suggest that the release of somatostatin and GH-releasing factor is regulated by catecholamine-containing neurons in the central nervous system (CNS) $(1,3)$.

Catecholamines were first implicated in $\mathrm{GH}$ regulation in man by the demonstration that insulin- and vasopressin-induced GH secretion was partially inhibited by the $\alpha$-adrenergic blocker, phentolamine (4). It was subsequently shown that L-dopa stimulates $\mathbf{G H}$ secretion in man $(5,6)$. Because L-dopa is a metabolic precursor of dopamine (DA), norepinephrine (NE), and epinephrine (EPI), it became essential to examine the effects of more selective dopaminergic and noradrenergic drugs on $\mathrm{GH}$ release. For example, CNS $\alpha$-adrenergic receptor stimulation with clonidine elicits $\mathrm{GH}$ release in man (7) and a number of lower species (8-11). Evidence concerning the role of brain DA in GH control is less consistent. In man, CNS DA receptor

\footnotetext{
${ }^{1}$ Abbreviations used in this paper: CNS, central nervous system; DA, dopamine; EPI, epinephrine; GH, growth hormone; NE, norepinephrine; NMT, norepinephrine $N$-methyl transferase; PRL, prolactin.
} 
stimulation with apomorphine causes $\mathrm{GH}$ release (12). However, activation or blockade of DA receptors in experimental animals has little effect on GH (8-10, 13), indicating that its effects may be specific to man.

Serial measurements of plasma GH levels in man and experimental animals show abrupt, spontaneous fluctuations $(1,14,15)$. For these oscillations to occur, the hypothalamic-pituitary connections must be intact (16). Because episodic GH secretion is particularly prominent in the male rat, this animal has provided a useful experimental model for the study of the adrenergic mechanisms involved in its regulation. In rats, a variety of noradrenergic synthesis inhibitors and receptor antagonists block the pulsatile secretion of $\mathbf{G H}$ (3). Moreover, noradrenergic antagonists prevent the increase in GH induced by morphine (17).

In all the previous studies, the noradrenergic agonists and antagonists used may also have affected transmission in EPI (adrenergic) svstems. Results of earlier experiments suggest that EPI stimulates $\mathrm{GH}$ in primates $(18)$ and rodents $(19,20)$ but not in man $(21-$ 24). The availability of several selective EPI synthesis inhibitors, developed for possible use as antihypertensive agents in man (25-28), have made it possible to alter the synthesis of EPI without affecting NE or DA. These compounds have been used in the present investigation to assess the involvement of brain EPI systems in regulation of episodic and morphine-induced GH secretion in the rat. Results of this study indicate that the CNS adrenergic system has a major function in the regulation of $\mathrm{GH}$ secretion.

\section{METHODS}

\section{Animals}

Male Sprague-Dawley rats (300-350 g, Harlan Industries Inc., Indianapolis, Ind.) were housed in temperature- and humidity-controlled laboratories with a 12-12-h light-dark cycle (lights on at 0600 ). The animals were given free access to laboratory chow and water.

\section{Drugs}

The selective EPI synthesis inhibitors, SK\& F 64139 and SK\& F 29661 (7,8-dichloro-1,2,3,4-tetrahydroisoquinoline and 1,2,3,4-tetrahydroisoquinoline-7-sulfonamide, respectively; Smith, Kline \& French Laboratories, Philadelphia, Pa.), which act by inhibiting norepinephrine $N$-methyltransferase (NMT, EC 2.1.1.28), were dissolved in $0.15 \mathrm{M} \mathrm{NaCl}$ (pH 7.0) to yield a final concentration of $25 \mathrm{mg} / \mathrm{ml}$ and administered intraperitoneally in doses of 10,25 , and $50 \mathrm{mg} / \mathrm{kg}$ body wt. A third NMT inhibitor, LY 78335 (2,3-dichloro- $\alpha$-methylbenzylamine; Eli Lilly \& Company Research Laboratories, Indianapolis, Ind.) was dissolved in the same vehicle and administered intraperitoneally in doses of 25 and $50 \mathrm{mg} / \mathrm{kg}$ body wt. SK \& F 64139 and LY 78335 cross the blood-brain barrier and inhibit central and peripheral EPI synthesis (26, 28). SK \& F 29661 inhibits only peripheral EPI synthesis, be- cause it does not cross the blood-brain barrier (27). The $\alpha$ agonist, clonidine (Boehringer Laboratories, Montreal, Quebec, Canada) was given intravenously in a dose of $150 \mu \mathrm{g} /$ kg. Morphine sulfate (Elkins-Sinn, Inc., Cherry Hill, N. J.) was diluted in $0.15 \mathrm{M} \mathrm{NaCl}$ to a final concentration of $0.5 \mathrm{mg} / \mathrm{ml}$ and administered intravenously in a dose of 3 $\mathrm{mg} / \mathrm{kg}$.

\section{Experimental procedure}

Experiment 1. Chronic indwelling cannulae were placed in the right atrium via the right external jugular vein and adapted to isolation test chambers by methods described previously (29). Sampling began after recovery of preoperative body weight (usually 1 wk postoperatively). Blood samples $(4 \times 50 \mu \mathrm{l})$ were withdrawn every $15 \mathrm{~min}$ and immediately centrifuged. The plasma was frozen at $-90^{\circ} \mathrm{C}$ until radioimmunoassay of $\mathrm{GH}$ and prolactin (PRL), and erythrocytes suspended in normal saline were returned to animals at the time of the next sample. Individual rats were usually used as their own control, receiving control injections on one experimental day and the drug(s) to be tested on a subsequent day. Animals (eight per group) recieved either the centrally active EPI synthesis inhibitors, SK\& F 64139, and LY 78335, the peripherally active, SK\&F 29661 , or saline vehicle at 0930 and were sampled for 3 or $6 \mathrm{~h}$ beginning at 1000 to encompass one or two $\mathrm{GH}$ secretory episodes. The animal's behavior was monitored through one-way observation ports in the cubicles.

In a parallel experiment, male rats (eight per group) were killed by cervical dislocation $1.5,2.5$, and $3.5 \mathrm{~h}$ after receiving either SK\& F 64139, SK\& F 29661, or normal saline at 0930 . Their brains were removed immediately, and hypothalami were dissected, weighted, snap-frozen on dry ice, and stored at $-90^{\circ} \mathrm{C}$ for subsequent extraction and determination of DA, NE, and EPI. The hypothalamic dissection was limited rostrally by the optic chiasm, caudally by the mammillary bodies, and laterally by the hypothalamic sulci, and the dorsal cut was $\sim 2 \mathrm{~mm}$ from the base of the brain.

Experiment 2. Clonidine or vehicle was given to SK\&F 64139-pretreated animals at 1105 by the methods described for Experiment 1.

Experiment 3. To determine whether blockade of central EPI synthesis affected morphine-stimulated GH, morphine sulfate $(3 \mathrm{mg} / \mathrm{kg}$ i.v.) or normal saline was administered at 1105 to animals pretreated with either SK\&F 64139 or vehicle at 0930 . Samples were removed from 1000-1300, as described above.

\section{GH and PRL radioimmunoassays}

GH and PRL were measured in duplicate by double-antibody radioimmunoassays with materials supplied by the National Pituitary Agency, as described previously (29). Values were determined using the weighted Rodbrad method (30) and expressed in terms of the National Institute of Arthritis, Metabolic, and Digestive Diseases reference preparation, rGH-RP-1 and rPRL-RP-1. The minimum detectable amount of $\mathrm{GH}$ was $2.5 \mathrm{ng} / \mathrm{ml}$, and the intraassay and interassay coefficients of variation were 3.8 and $9.6 \%$, respectively (means of 10 determinations). The minimum detectable amount of PRL was $1.0 \mathrm{ng} / \mathrm{ml}$, and the intraassay and interassay coefficients of variation were 3.4 and $10.9 \%$, respectively (means of six determinations). 


\section{Catecholamine assay}

Concentrations of EPI, NE, and DA in the hypothalamus were measured by a sensitive radioenzymatic assay. The catecholamines were extracted according to the method of Sole and Hussain (31) and separated by thin-layer chromatography according to Peuler and Johnson (32). The minimum detectable level of each catecholamine was $10 \mathrm{pg}$. All samples were measured in the same assay to avoid interassay variation.

\section{Analysis of data}

The secretory profiles of $\mathrm{GH}$ were compared in drugtreated and control animals to determine $(a)$ the effect of SK \& F 64139, SK \& F 29661, and LY 78335 on pulsatile GH and PRL release and $(b)$ the effects of clonidine and morphine on GH secretion in vehicle- and/or SK\& F 64139-pre- treated animals. The effects of saline vehicle, SK\&F 64139 , SK\&F 29661, and LY 78335 on GH and PRL levels over time were analyzed by two factor, repeated measures analyses of variance (drugs $\times$ time). In addition, single-factor analyses of variance, followed by Newman-Keuls tests, were used to compare $(a)$ plasma GH and PRL levels in SK\&F 64139-, SK\&F 29661-, and LY 78335-treated rats and (b) plasma $\mathrm{GH}$ levels from 1100 to 1300 in vehicle- or SK\& F 64139-pretreated animals that received drugs at 1105 . Single-factor analyses of variance and Newman-Keuls tests (33) also were used to compare tissue levels of catecholamines $1.5,2.5$, and $3.5 \mathrm{~h}$ after receiving SK \& F 64139, SK \& F 29661, or vehicle. $P<0.05$ was considered significant.

\section{RESULTS}

Effects of SK\&F 64139, SKむF 29661, and LY 78335 on episodic GH and PRL secretion. The pattern of

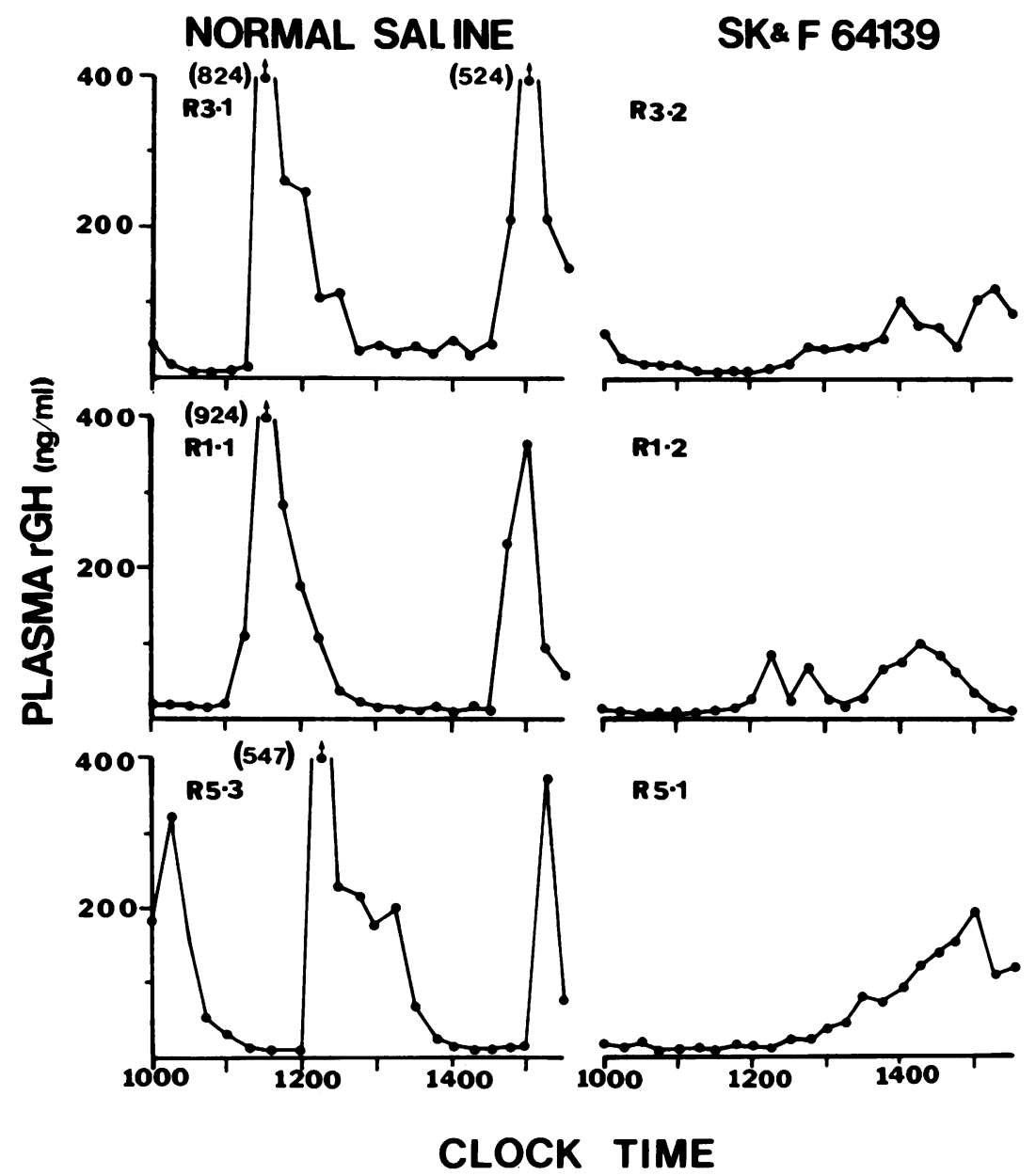

FIGURE 1 Effects of SK\& F 64139, a central EPI synthesis inhibitor, on episodic GH secretion in individual male rats sampled for $5.5 \mathrm{~h}$. Normal saline-treated (intraperitoneally) control animals showed typical episodic GH release with pulses occurring between 1100 and 1200 and between 1400 and 1500 . SK \& F $64139(50 \mathrm{mg} / \mathrm{kg}$ i.p.) completely inhibited the first and partially suppressed the second pulse. Normal saline or SK\& F 64139 were administered at 0930 . " $R$ " followed by a number in the upper left corner of each graph refers to individual rats. 
GH secretion in individual animals confirmed previous observations (34) that male rats kept on a constant light-dark cycle have episodes of $\mathrm{GH}$ release that occur at approximately the same time (1100-1200 and 1300-1500) (Fig. 1, left). The centrally active SK\&F 64139 suppressed $(P<0.001)$ pulsatile GH for $6 \mathrm{~h}$ (Fig. 1 , right) in a dose-dependent manner (Fig. 2). Administration of the other centrally active EPI antangonist, LY 78335, also suppressed $(P<0.001) \mathrm{GH}$ release, and this effect also was dose related (Fig. 3). However, the peripheral antangonist, SK \& F 29661 (50 $\mathrm{mg} / \mathrm{kg}$ i.p.) had no effect on $\mathrm{GH}$ when compared with the normal saline control group (Fig. 4).

SK\& F 64139 caused a significant, dose-related increase in mean 3-h plasma levels of PRL (Table I). Administration of the peripheral EPI synthesis inhibitor, SK\& F 29661, also elevated PRL levels (Table I). However, LY 78335 did not significantly affect plasma PRL when compared with the normal saline control group (Table I). None of the drugs caused a discernible change in the animals' behavior, and, specifically, there were no indications that the drug-treated animals were stressed.

Effects of SKむF 64139 and SK\&F 29661 on hypothalamic EPI. As demonstrated previously $(26,35)$, the centrally active EPI synthesis inhibitor, SK\&F $64139(50 \mathrm{mg} / \mathrm{kg}$ i.p.), caused a significant reduction $(P<0.05)$ in the hypothalamic concentration of EPI in male rats from 1.5 to $3.5 \mathrm{~h}$ after administration, whereas SK\&F 29661, the peripheral EPI synthesis inhibitor, had no effect when compared with time-

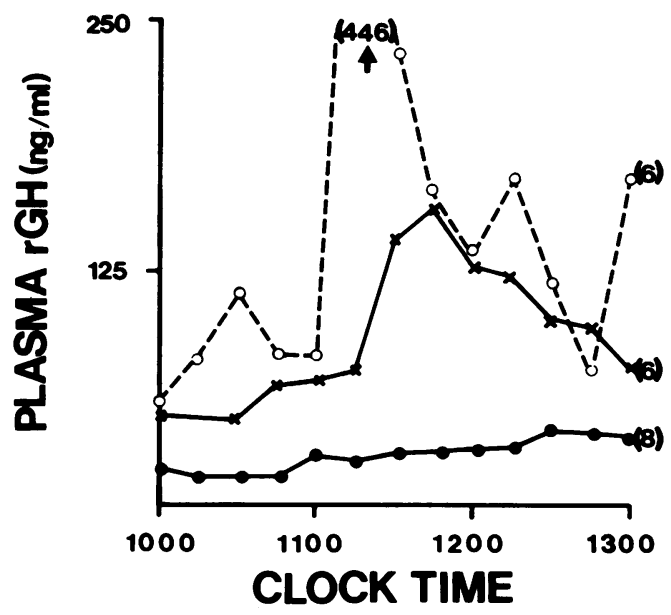

FIgure 2 Dose-related suppression of episodic GH secretion by SK \& F 64139 administered at 0930 . SK \& F 64139 inhibited $(P<0.002) \mathrm{GH}$ release in doses of $25(X)$ and $50(\bullet) \mathrm{mg} /$ $\mathrm{kg}$ i.p. The $10 \mathrm{mg} / \mathrm{kg}$ dose $(O)$ did not suppress GH significantly. Standard errors of the mean were omitted for clarity. In this and subsequent figures numbers in parentheses at 1300 refer to the number of animals in each treatment group.

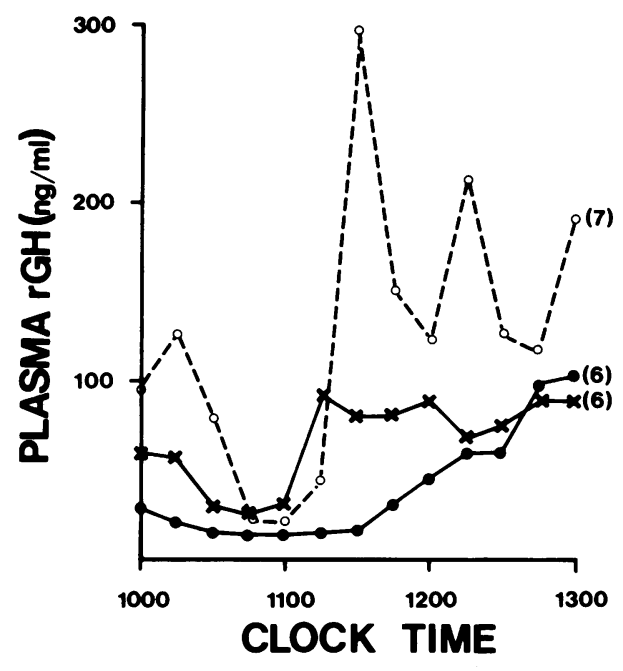

Figure 3 Dose-related inhibition of pulsatile GH release by the central EPI synthesis inhibitor, LY 78335, administered at 0930 . Doses of $25(X)$ and $50(\bullet) \mathrm{mg} / \mathrm{kg}$ i.p. inhibited $(P<0.01)$ GH. (O) Standard saline control. Standard errors were omitted for clarity.

matched controls (Fig. 5). Neither of the drugs affected tissue levels of DA or NE (Table II).

Effect of clonidine on GH in SKむF 64139-pretreated male rats. To test whether the inhibition of GH release by SK\& F 64139 could be reversed by activation of central postsynaptic $\alpha$-adrenergic receptors, clonidine $(150 \mu \mathrm{g} / \mathrm{kg})$ or vehicle were administered at a time (1105) that coincided with the anticipated occurrence of a GH burst, as had been documented in the same animal on a previous control day. In SK \& F 64139-pretreated rats, clonidine caused a significant elevation in mean GH levels above salineinjected controls $(P<0.0001$, Fig. 6$)$. Clonidine-stimulated mean GH levels were comparable to those seen during spontaneous pulses in untreated animals.

Effect of morphine on GH in SKdF 64139-pretreated male rats. To determine whether EPI was involved in morphine-induced $\mathrm{GH}$ release, morphine sulfate $(3 \mathrm{mg} / \mathrm{kg}$ i.v. at 1105$)$ was administered to vehicle- or SK \& F 64139-pretreated male rats. In the vehicle-pretreated group, morphine had an immediate stimulatory effect on $\mathrm{GH}$ that resulted in mean plasma levels $>1,000 \mathrm{ng} / \mathrm{ml}$ (Fig. 7), significantly higher than the $(P<0.01)$ group receiving saline vehicle (not shown). Previous studies have shown that morphinestimulated GH release in the rat is inhibited by naloxone (17), indicating that this is a specific effect due to activation of opiate receptors. In the present study, the stimulatory effect of morphine on GH was completely blocked by pretreatment with SK\&F 64139 (Fig. 7). 


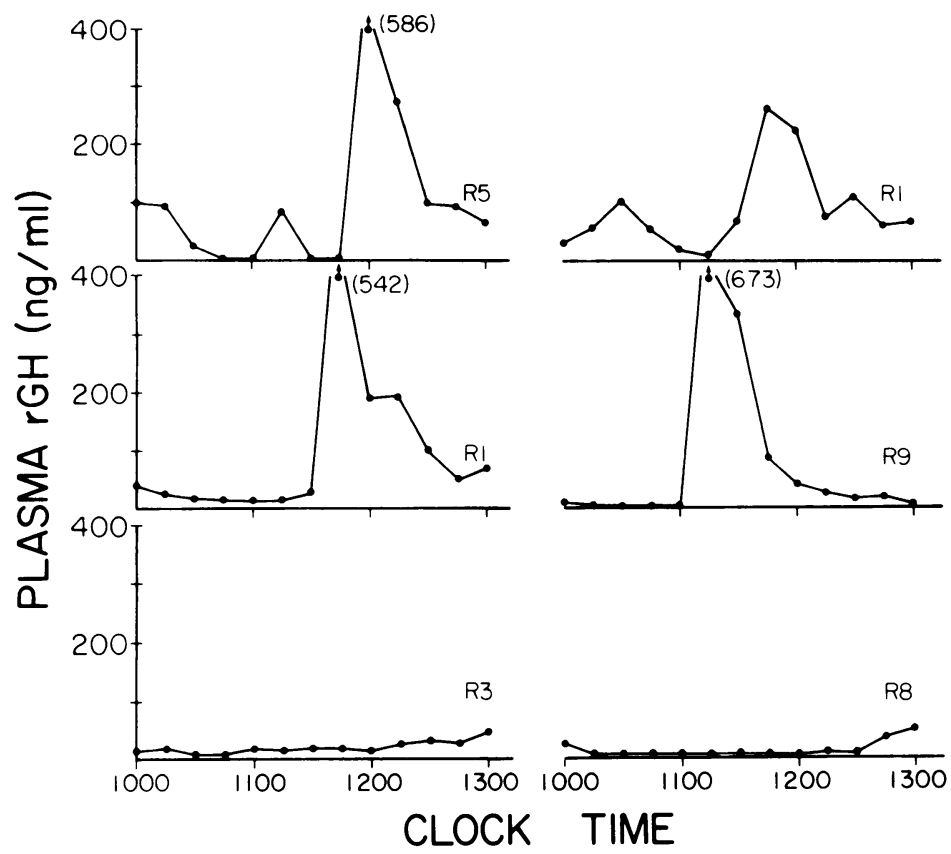

Figure 4 Effects of SK\&F 29661, a peripheral (EPI) synthesis inhibitor, and SK \& F 64139 on episodic GH secretion in individual male rats. Normal saline (intraperitoneally)- and SK\&F 29661 (50 mg/kg i.p.)-treated animals showed pulsatile $\mathrm{GH}$ release (top and middle, respectively). SK \& F 64139 (50 mg/kg i.p.) completely suppressed episodic GH secretion (bottom). The letter $\mathrm{R}$ followed by a number in the lower right corner of each graph refers to individual rats.

\section{DISCUSSION}

The results of this study show that inhibition of CNS EPI synthesis by SK\&F 64139 and LY 78335 completely suppressed physiologic, pulsatile, GH release

TABLE I

Effects of SKむF 64139, SKむF 29661, and LY 78335 on Mean 3-h PRL Levels

\begin{tabular}{lc}
\hline & Plasma PRL \\
\hline & $n g / m l$ \\
Normal saline (i.p.) & $4.7 \pm 1.1(10)$ \\
SK\&F 29661 (50 mg/kg i.p.) & $20.2 \pm 4.8(10)^{\circ}$ \\
SK\&F 64139 (i.p.) & \\
$10 \mathrm{mg} / \mathrm{kg}$ & $14.4 \pm 4.1(6)^{\circ}$ \\
$25 \mathrm{mg} / \mathrm{kg}$ & $25.8 \pm 7.5(6)^{\circ}$ \\
$50 \mathrm{mg} / \mathrm{kg}$ & $39.7 \pm 8.0(9)^{\circ}$ \\
$\mathrm{LY} 78335$ (i.p.), & \\
$25 \mathrm{mg} / \mathrm{kg}$ & $6.5 \pm 1.5(6)$ \\
$50 \mathrm{mg} / \mathrm{kg}$ & $9.7 \pm 1.3(6)$ \\
\hline
\end{tabular}

Values are given as mean $\pm \mathrm{SE}$. Numbers in parentheses indicate the number of animals in each group.

${ }^{\circ} P<0.05$ compared with normal saline. in male rats. In contrast, the peripheral EPI synthesis blocker, SK \& F 29661, had no effect on GH secretion. This indicates that inhibition of brain rather than ad-

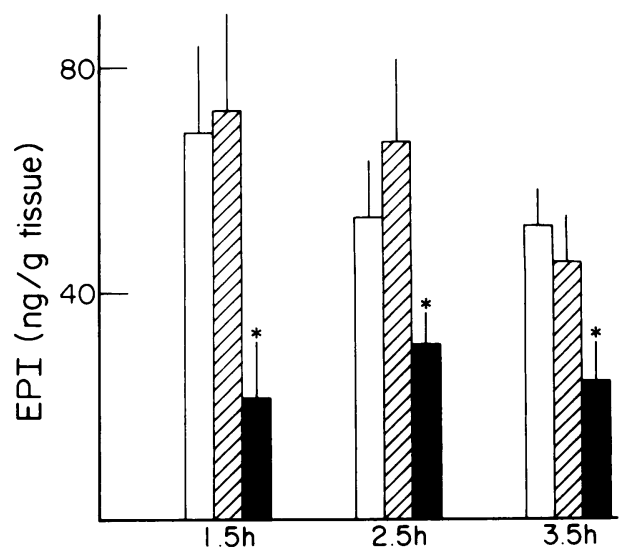

Figure 5 Effects of SK\& F 29661 and SK \& F 64139 on the concentration of EPI in the hypothalamus 1.5, 2.5, and 3.5 $\mathrm{h}$ after administration at 0930 . SK \& F 64139 (solid bar; 50 $\mathrm{mg} / \mathrm{kg}$ i.p.) caused a significant reduction in EPI, but 29661 (striped bar; $50 \mathrm{mg} / \mathrm{kg}$ i.p.) had no significant effect. (open bar, normal saline intraperitoneally) Asterisk indicates $P<0.05$. There were eight animals in each treatment group. Vertical lines represent SEM. 
TABLE II

Effects of SKUF 29661 and SKUF 64139 on Hypothalamic Concentrations of DA and $N E$ in Male Rats 1.5, 2.5, and $3.5 h$ after Injection

\begin{tabular}{cccc}
\hline & $\begin{array}{c}\text { Normal saline } \\
\text { (i.p.) }\end{array}$ & \multicolumn{1}{c}{$\begin{array}{c}\text { SKF 29661 } \\
(50 \mathrm{mg} / \mathrm{kg} \text { i.p. })\end{array}$} & $\begin{array}{c}\text { SKF 64139 } \\
(50 \mathrm{mg} / \mathrm{kg} \text { i.p. })\end{array}$ \\
\hline & & $n g / g$ tissue & \\
$\mathrm{DA}$ & & & \\
$1.5 \mathrm{~h}$ & $223.5 \pm 17.8$ & $213.4 \pm 9.9$ & $242.8 \pm 6.5$ \\
$2.5 \mathrm{~h}$ & $221.8 \pm 11.4$ & $219.6 \pm 10.3$ & $250.1 \pm 11.8$ \\
$3.5 \mathrm{~h}$ & $206.1 \pm 16.6$ & $190.9 \pm 13.3$ & $231.2 \pm 15.0$ \\
$\mathrm{NE}$ & & & \\
$1.5 \mathrm{~h}$ & $1,498.5 \pm 60.8$ & $1,384.0 \pm 63.0$ & $1,313.0 \pm 36.0$ \\
$2.5 \mathrm{~h}$ & $1,503.0 \pm 118.0$ & $1,433.0 \pm 111.0$ & $1,327.0 \pm 7.5$ \\
$3.5 \mathrm{~h}$ & $1,275.2 \pm 61.3$ & $1,300.0 \pm 62.0$ & $1,300.0 \pm 84.0$ \\
\hline
\end{tabular}

Each group consisted of eight animals.

renal EPI synthesis is responsible. The inhibition of episodic GH secretion by SK\&F 64139 was accompanied by a significant reduction in the hypothalamic concentration of EPI, whereas SK\&F 29661 had no effect. Earlier studies have shown that LY 78335 inhibited hypothalamic EPI synthesis (28). None of these drugs altered hypothalamic NE nor DA.

Previous attempts to investigate the function of EPI in $\mathrm{GH}$ regulation in man and experimental animals were limited by the poor penetrability of the bloodbrain barrier by EPI and the unavailability of agents that directly affect brain EPI neurotransmission. In

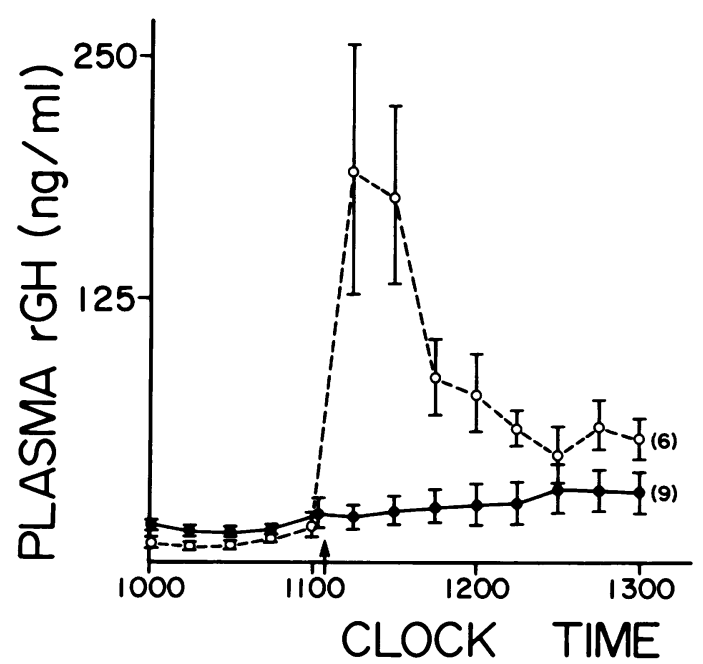

Figure 6 Effect of clonidine, a centrally active $\alpha$-adrenergic receptor agonist, on GH secretion in SK \& F 64139-pretreated (0930) male rats. Clonidine $(O ; 150 \mu \mathrm{g} / \mathrm{kg}$ i.v.) administration at 1105 (indicated by arrow) caused a significant elevation in GH levels (O; saline intravenously at 1105). Vertical lines represent SEM. man, peripheral administration of EPI in doses sufficient to produce significant hyperglycemia did not induce GH secretion (21-23) nor did it inhibit argininestimulated $\mathrm{GH}$ release (24). However, large doses of EPI initiated a marked and prompt increase in plasma GH levels in female rhesus monkeys (18). Moreover, intracerebroventricular or intravenous EPI administration to rats caused release of bioassayable GH (19,

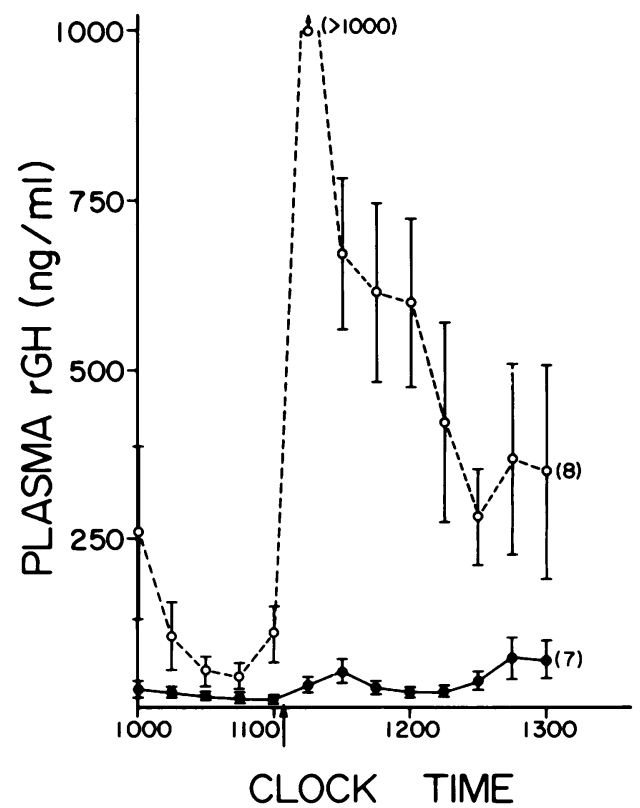

Figure 7 Effects of morphine sulfate on GH secretion in SK\& F 64139(0, $50 \mathrm{mg} / \mathrm{kg}$ i.p.)- and normal saline $(O$, intraperitoneally)-pretreated (0930) male rats. Morphine sulfate ( $3 \mathrm{mg} / \mathrm{kg}$ i.v.) administration (1105, indicated by arrow) to saline-pretreated rats caused a significant elevation in $\mathbf{G H}$ levels. This effect was blocked completely by pretreatment with SK \& F 64139. Vertical lines represent SEM. 
20). Data from the present experiments, in which selective EPI antagonists were used, indicate that the central EPI system has a major function in the generation of episodic $\mathrm{GH}$ secretion in the rat.

Morphine and the endogenous opioid peptides, metenkephalin and $\beta$-endorphin, have a potent stimulatory effect on $\mathrm{GH}$ secretion in numerous experimental animals, an effect prevented by the specific opiate receptor blocker, naloxone (1, 17, 36-38). Furthermore, the synthetic enkephalin analogue, FK-33-824, causes $\mathrm{GH}$ release in man (39). None of the opioids appear to act directly at the pituitary level, and it is likely that they influence the release of $\mathrm{GH}$ either by modulating the secretion of releasing-inhibiting factors and/or by affecting neurotransmitters $(40,41)$. Evidence supporting the latter hypothesis was provided in a recent study demonstrating that $\alpha$-adrenergic receptor blockade with phenoxybenzamine or inhibition of NE and EPI synthesis with diethyldithiocarbamate, a dopamine- $\beta$-hydroxylase inhibitor, abolished the GH-releasing effect of morphine in the rat (17). These effects were attributed to noradrenergic mechanisms. Data from the present study suggest that morphine enhances GH secretion by activation of CNS EPI systems, because the selective EPI antagonist, SK\&F 64139 , completely blocked morphine-induced GH release. These results do not necessarily exclude a similar role for $\mathrm{NE}$.

Previous studies have shown that clonidine restores pulsatile GH release in rats after blockade of $\mathrm{NE}$ and EPI synthesis with FLA-63, a dopamine- $\beta$-hydroxylase inhibitor (11). In the present study, clonidine administration to SK\& F 64139-pretreated animals elevated $\mathrm{GH}$ to levels that occur during episodic release. Clonidine also stimulates $\mathrm{GH}$ secretion in man and several species of experimental animals (7-11). The stimulatory action of clonidine is most likely due to activation of postsynaptic $\alpha$-adrenergic receptors. Clonidine activates postsynpatic or presynaptic EPI receptors in discrete brain regions (42). It is not possible at present to determine whether the effect of clonidine is due to activation of receptors normally occupied by NE or EPI. However, the ability of clonidine to stimulate GH release in SK\& F 64139-treated rats demonstrates that the EPI synthesis inhibitor does not compromise the ability of the pituitary gland to release GH.

In addition to its NMT-inhibiting actions, SK\&F 64139 has been reported to have some adrenergic blocking effects mediated via $\alpha_{2}$ - and $\alpha_{1}$-adrenoreceptors in vitro (43). Thus, caution should be exercised when interpreting the interaction between SK\&F 64139 , EPI, and GH, because NMT inhibition or $\alpha$ receptor blockade could produce similar effects on $\mathrm{GH}$ release. It is unlikely that these $\alpha$-blocking actions can account for the inhibitory effects of SK\&F 64139 on pulsatile GH for several reasons. First, SK \& F 64139 has little postsynaptic adrenergic blocking action, but does have presynaptic antagonistic properties (43). However, this would enhance NE and EPI release (44), and thus would not be expected to block $\mathrm{GH}$ release. Second, central EPI synthesis inhibition by LY 78335, which does not possess $\alpha$-blocking properties (28), also inhibited GH secretion. Finally, postsynaptic $\alpha$-blockade by SK \& F 64139 would be expected to inhibit clonidine-stimulated GH release (45), but it did not.

The tetrahydroisoquinoline NMT inhibitors, SK \& F 64139 and SK \& F 29661, both elevated PRL levels. The mechanism underlying this effect is unknown but does not appear to be related to EPI synthesis inhibition, because elevation of PRL was not obtained with the benzylamine NMT inhibitor, LY 78335. It is possible that the SK\&F compounds exert a direct action on pituitary lactotrophs unrelated to their effects on EPI synthesis.

The dissociation between the effects of the SK\&F agents and LY 78335 on PRL also argue against the possibility that the drug-induced suppression of $\mathrm{GH}$ release is due to stress. Stress suppresses pulsatile GH release and stimulates PRL release in rats (46). Both SK\&F 64139 and SK\&F 29661 elevated plasma PRL, but only SK\&F 64139 suppressed GH secretion. LY 78335 also inhibited pulsatile GH release but had no effect on PRL. These dissociations favor the interpretation that the inhibitory effects on $\mathrm{GH}$ are due to inhibition of central adrenergic neurotransmission.

Because octopamine can serve as an alternate substrate for NMT (47), in addition to EPI it is conceivable that the result of that interaction, or others like it, could have a role in CNS regulation of $\mathrm{GH}$ secretion. However, the distribution and roie of octopamine in the mammalian CNS are unclear, and there are no reports that other known metabolic products of alternative NMT substrates are active at $\alpha$-receptor sites within the CNS.

In summary, results of the present experiments indicate $(a)$ that central EPI systems exert a major stimulatory effect on episodic GH secretion, $(b)$ that morphine-stimulated $\mathrm{GH}$ release is mediated by central EPI systems, and (c) that clonidine enhances $\mathrm{GH}$ release by activation of postsynaptic $\alpha$-adrenergic receptors. The selective EPI antagonist, SK \& F 64139, is currently being investigated in man as an antihypertensive agent (48). This drug may also prove useful in the diagnosis and treatment of disorders of GH secretion.

\section{ACKNOWLEDGMENTS}

We especially thank Charles Longserre and Cecil Lynch for their sincere dedication and expert technical assistance. Mrs. Ann Marie Bobrowski provided excellent secretarial assis- 
tance. Drs. Solomon Solomon, John Whitaker, and Seymour Reichlin provided expert critical reviews of this work. The generous gift of SK\&F 64139 and SK\&F 29661 by Dr. R. Pendleton and Smith Kline \& French Laboratories and of LY 78335 by Dr. R. Fuller and Eli Lilly \& Company Research Laboratories is appreciated greatly.

We are grateful to the Research Service of the Veterans Administration and the National Institutes of Health (grants HD-13703 and GM 2666-20) for financial support. The generous provision of radioimmunoassay materials by the $\mathrm{Na}$ tional Pituitary Agency is acknowledged.

\section{REFERENCES}

1. Martin, J. B., P. Brazeau, G. S. Tannenbaum, J. O. Willoughby, J. Epelbaum, L. C. Terry, and D. Durand. 1978. Neuroendocrine organization of growth hormone regulation. In The Hypothalamus. S. Reichlin, R. J. Baldessarini, and J. B. Martin, editors. Raven Press, New York. 56: 329-357.

2. Brazeau, P., W. Vale, R. Burgus, N. Ling, M. Butcher, J. Rivier, and R. Guillemin. 1973. Hypothalamic polypeptide that inhibits the secretion of immunoreactive pituitary growth hormone. Science (Wash. D. C.). 179: 77-79.

3. Martin, J. B. 1980. Functions of central nervous system neurotransmitters in regulation of growth hormone secretion. Fed. Proc. 39: 2902-2906.

4. Blackard, W. G., and S. A. Heidingsfelder. 1968. Adrenergic receptor control mechanism for growth hormone secretion. J. Clin. Invest. 47: 1407-1414.

5. Boyd, A., H. Lebovitz, and J. B. Pfeiffer. 1970. Stimulation of human growth hormone secretion by L-dopa. N. Engl. J. Med. 283: 1425-1429.

6. Lal, S., J. B. Martin, C. de la Vega, and H. G. Friesen. 1975. Comparison of the effect of apomorphine and Ldopa on serum growth hormone levels in man. Clin. Endocrinol. 4: 277-285.

7. Lal, S., G. Tolis, J. B. Martin, G. M. Brown, and H. Guyda. 1975. Effect of clonidine on growth hormone, prolactin, luteinizing hormone, follicle-stimulating hormone, and thyroid-stimulating hormone in the serum of normal man. J. Clin. Endocrinol. Metab. 41: 827-832.

8. Chambers, J. W., and G. M. Brown. 1976. Neurotransmitter regulation of growth hormone and $\mathrm{ACTH}$ in the rhesus monkey: effects of biogenic amines. Endocrinology. 98: 420-428.

9. Lovinger, R., J. Holland, S. Kaplan, M. Grumbach, A. J. Boryczka, R. Shackelford, J. Salmon, I. A. Reid, and W. F. Ganong. 1976. Pharmacological evidence for stimulation of growth hormone secretion by a central noradrenergic system in dogs. Neuroscience. 1: 443-450.

10. Durand, D., J. B. Martin, and P. Brazeau. 1977. Evidence for a role of $\alpha$-adrenergic mechanisms in regulation of episodic growth hormone secretion in the rat. Endocrinology. 100: 722-728.

11. Terry, L. C., and J. B. Martin. 1981. Evidence for $\alpha$ adrenergic regulation of episodic growth hormone and prolactin secretion in the undisturbed male rat. Endocrinology. 108: 1869-1873.

12. Lal, S., C. E. de la Vega, T. L. Sourkes, and H. G. Friesen. 1973. Effect of apomorphine on growth hormone and follicle-stimulating hormone levels in human serum. J. Clin. Endocrinol. Metab. 37: 719-724.

13. Willoughby, J. O., P. Brazeau, and J. B. Martin. 1977. Pulsatile growth hormone and prolactin: effects of $(+)$ butaclamol, a dopamine receptor blocking agent. Endocrinology. 101: 1298-1303.

14. Quabbe, H-J., E. Schilling, and H. Helge. 1966. Pattern of growth hormone secretion during a 24-hour fast in normal adults. J. Clin. Endocrinol. Metab. 26: 11731177.

15. Takahashi, Y., D. M. Kipnis, and W. H. Daughaday. 1968. Growth hormone secretion during sleep. J. Clin. Invest. 47: 2079-2090.

16. Martin, J. B. 1978. Bowditch lecture: brain mechanisms for integration of growth hormone secretion. Physiologist. 22: 23-29.

17. Koenig, J., M. A. Mayfield, R. J. Coppings, S. M. McCann, and L. Krulich. 1980. Role of central nervous system neurotransmitters in mediating the effects of morphine on growth hormone-and prolactin-secretion in the rat. Brain. Res. 197: 453-468.

18. Meyer, V., and K. Knobil. 1967. Growth hormone secretion in the unanesthetized rhesus monkey in response to noxious stimuli. Endocrinology. 80: 163-171.

19. Muller, E. E., T. Saito, A. Arimura, and A. V. Schally. 1967. Blockade of release of growth hormone by brain norepinephrine depletors. Endocrinology. 80: 471-476.

20. Muller, E. E., P. Dal Pra, and A. Pecile. 1968. Influence of brain neurohumors injected into the lateral ventricle of the rat on growth hormone release. Endocrinology. 83: 893-896.

21. Roth, J., M. Glick, R. S. Yalow, and S. A. Berson. 1963. Hypoglycemia: a potent stimulus to secretion of growth hormone. Science (Wash. D. C.). 140: 987-988.

22. Schalch, D. S. 1967. The influence of physical stress and exercise on growth hormone and insulin secretion in man. J. Lab. Clin. Med. 69: 256-269.

23. Massara, F., and E. Strumina. 1970. Increase in plasma growth hormone concentration in man after infusion of adrenaline-propranolol. J. Endrocrinol. 47: 95-100.

24. Rabinowitz, D., T. J. Merimee, J. K. Nelson, R. B. Schultz, and J. A. Burgess. 1968. The influence of proteins and amino acids on growth hormone release in man. In Growth Hormone. A. Pecile and E. E. Muller, editors. Proceedings International Symposium Growth Hormone, 1967, Excerpta Medica Foundation, International Congress Series No. 158. 105-115.

25. Pendleton, R. G., J. P. McCafferty, and J. M. Roesler. 1980. Effects of PNMT inhibitors upon cardiovascular changes induced by hemorrhage in the rat. Eur. J. Pharmacol. 66: 1-10.

26. Sauter, A. M., J. Y. Lew, Y. Baba, and M. Goldstein. 1977. Effect of phenylethanolamine $N$-methyl transferase and dopamine- $\beta$-hydroxylase inhibition on epinephrine levels in the brain. Life Sci. 21: 261-266.

27. Pendleton, R. G., G. Gessner, G. Weiner, B. Jenkins, J. Sawyer, W. Bondinell, and A. Intoccia. 1979. Studies on SK\& F 29661, an organ specific inhibitor of phenylethanolamine- $N$-methyltransferase. J. Pharmacol. Exp. Ther. 208: 24-30.

28. Fuller, R. W., and K. W. Perry. 1977. Lowering of epinephrine concentration in rat brain by 2,3 -dichloro- $\alpha$ methylbenzylamine, an inhibitor of norepinephrine $N$ methyltransferase. Biochem. Pharmacol. 26: 2087-2090.

29. Terry, L. C., and J. B. Martin. 1978. Hypothalamic-pituitary responses in intracranial self-stimulation in the rat. Brain Res. 157: 89-104.

30. Rodbard, D. 1974. Statistical quality control and routine data processing for radioimmunoassays (RIA) and immunoradiometric assays (IRMA). Clin. Chem. 20: 12551270 . 
31. Sole, M. J., and M. N. Hussain. 1977. A simple, specific, radio-enzymatic assay for the simultaneous measurement of picogram quantities of norepinephrine, epinephrine, and dopamine in plasma and tissues. Biochem. Med. 18: 301-307.

32. Peuler, J. D., and G. A. Johnson. 1977. Simultaneous single isotope radioenzymatic assay of plasma norepinephrine, epinephrine, and dopamine. Life Sci. 21: 625636 .

33. Winer, B. J. 1971. Statistical Principles In Experimental Design. McGraw Hill Book Co., Inc., New York. 1-907.

34. Tannenbaum, G. S., and J. B. Martin. 1976. Evidence for an endogenous ultradian rhythm governing growth hormone secretion in the rat. Endocrinology. 98: 562570.

35. Crowley, W. R., and L. C. Terry. 1981. Effects of an epinephrine synthesis inhibitor, SK \& F 64139, on the secretion of luteinizing hormone in ovariectomized female rats. Brain Res. 204: 231-235.

36. Van Vugt, D. A., and J. Meites. 1980. Influence of endogenous opiates on anterior pituitary function. Fed. Proc. 39: 2533-2538.

37. Imura, H., Y. Kato, H. Katakami, and N. Matsushita. 1981. Effect of CNS peptides on hypothalamic regulation of pituitary secretion. In Neurosecretion and Brain Peptides. J. B. Martin, S. Reichlin, and K. L. Bick, editors. Raven Press, New York. 557-570.

38. Chihara, K., A. Arimura, D. H. Coy, and A. V. Schally. 1978. Studies on the interaction of endorphins, substance $P$, and endogenous somatostatin in growth hormone and prolactin release in rats. Endocrinology. 102: 281-290.

39. Graffenreid, B., E. Del Pozo, J. Roubicek, E. Krebs, W Poldinger, P. Burmeister, and L. Kerp. 1978. Effects of the synthetic enkephalin analogue FK 33-824 in man. Nature (Lond.). 272: 729-730.

40. Rivier, C., W. Vale, N. Ling, M. Brown, and R. Guillemin. 1977. Stimulation in vivo of the secretion of prolactin and growth hormone by $\beta$-endorphin. Endocrinology. 100: 238-241.

41. Dupont, A., L. Cusan, M. Garon, F. Labrie, and C. H. Li. 1977. $\beta$-Endorphin: stimulation of growth hormone release in vivo. Proc. Natl. Acad. Sci. U. S. A. 74: 358359.

42. Fuxe, K., G. Jonsson, P. Bolme, K. Anderson, L. F. Agnati, M. Goldstein, and T. Hokfelt. 1979. Reduction in adrenalin turnover in cardiovascular areas of rat medulla oblongata by clonidine. Acta Physiol. Scand. 107: 177179.

43. Drew, G. M. 1981. $\alpha_{2}$-Adrenoreceptor-blocking action of the phenylethanolamine- $N$-methyl-transferase inhibitor SK\& F 64139. J. Pharm. Pharmacol. 33: 188-189.

44. Starke, K. 1977. Regulation of noradrenaline release by presynaptic receptor systems. Rev. Physiol. Biochem. Pharmacol. 77: 1-124.

45. Schaub, C., M. T. Bluet-Pajot, F. Mounier, A. Segalen, and J. Duhoult. 1980. Effects of noradrenergic agonists and antagonists on growth hormone secretion under gamma-hydroxybutyrate narco-analgesia in the rat. Psychoneuroendocrinology. 5: 139-146.

46. Terry, L. C., A. Saunders, J. Audet, J. O. Willoughby, P. Brazeau, and J. B. Martin. 1977. Physiologic secretion of growth hormone and prolactin in male and female rats. Clin. Endocrinol. 6: 19s-28s.

47. Nagatsu, T. 1973. Biochemistry of Catecholamines. University Park Press, Baltimore. 1-353.

48. Dubb, J. W., R. M. Stote, F. Alexander, A. P. Intoccia, M. Geczy, and R. G. Pendleton. 1979. Studies with a PNMT inhibitor. Clin. Pharmacol. Ther. 25: 837-843. 